\title{
Erratum to: Geostatistical characterization of soil moisture and chloride distribution in deep vadose profiles of the Badain Jaran Desert, Northwestern China
}

\author{
Feng Pan $\cdot$ Jinzhu Ma $\cdot$ Xangyang Zhou $\cdot$
}

W. Mike Edmunds $\cdot$ John B. Gates

Published online: 1 October 2013

(C) Springer-Verlag Berlin Heidelberg 2013

\section{Erratum to: Environ Earth Sci (2013) 70:977-991 \\ DOI 10.1007/s12665-012-2188-8}

The authors would like to correct errors in the original publication as detailed below.

The correct version of the author list is given here:

Feng Pan $\cdot$ Jinzhu Ma $\cdot$ Xangyang Zhou $\cdot$

W. Mike Edmunds · John B. Gates

F. Pan

College of Atmospheric Sciences, Lanzhou University, 222 South Tianshui Road, Lanzhou 730000, China

e-mail: Panfeng@1zu.edu.cn

\section{F. Pan $\cdot$ J. Ma $\cdot$ X. Zhou}

Key Laboratory of Western China's Environmental Systems (Ministry of Education), Lanzhou University, 222 South Tianshui Road, Lanzhou 730000, China e-mail: jzma@lzu.edu.cn

W. Mike Edmunds Oxford Centre for Water Research, Oxford University, South Parks Road, Oxford OX1 3QY, UK

\section{J. B. Gates}

Department of Earth and Atmospheric Sciences, University of Nebraska-Lincoln, 217 Bessey Hall, Lincoln, NE 68588-0340, USA

The online version of the original article can be found under doi:10.1007/s12665-012-2188-8.

\section{F. Pan}

College of Atmospheric Sciences, Lanzhou University,

222 South Tianshui Road, Lanzhou 730000, China

e-mail: Panfeng@1zu.edu.cn

F. Pan · J. Ma $(\bowtie) \cdot$ X. Zhou

Key Laboratory of Western China's Environmental Systems (Ministry of Education), Lanzhou University, 222 South Tianshui Road, Lanzhou 730000, China e-mail: jzma@1zu.edu.cn

W. Mike Edmunds Oxford Centre for Water Research, Oxford University,

South Parks Road, Oxford, OX1 3QY, UK

\section{J. B. Gates}

Department of Earth and Atmospheric Sciences, University of Nebraska-Lincoln, 217 Bessey Hall, Lincoln, NE 68588-0340, USA 